\title{
Surface potential change in bioactive polymer during the process of biomimetic apatite formation in a simulated body fluid $\dagger$
}

\author{
Isabel B. Leonor, ${ }^{* a b c}$ Hyun-Min Kim, ${ }^{d}$ Francisco Balas, ${ }^{c}$ Masakazu Kawashita, ${ }^{e}$ Rui L. Reis, ${ }^{a b}$ \\ Tadashi Kokubo ${ }^{c}$ and Takashi Nakamura ${ }^{f}$
}

Received 15th May 2007, Accepted 13th August 2007

First published as an Advance Article on the web 4th September 2007

DOI: $10.1039 / b 707304 f$

\begin{abstract}
A bioactive polyethylene substrate can be produced by incorporation of sulfonic functional groups $\left(-\mathrm{SO}_{3} \mathrm{H}\right)$ on its surface and by soaking in a calcium hydroxide saturated solution. Variation of the surface potential of the polyethylene modified with $-\mathrm{SO}_{3} \mathrm{H}$ groups with soaking in a simulated body fluid (SBF) was investigated using a laser electrophoresis zeta-potential analyzer. To complement the study using laser electrophoresis, the surface was examined by X-ray photoelectron spectroscopy (XPS), thin film X-ray diffraction (TF-XRD), field-emission scanning electron microscopy (FE-SEM) and energy-dispersive electron X-ray spectroscopy (EDS).

Comparing the zeta potential of sulfonated and $\mathrm{Ca}(\mathrm{OH})_{2}$-treated polyethylene with its surface structure at each interval of these soaking times in SBF, it is apparent that the polymer has a negative surface potential when it forms $-\mathrm{SO}_{3} \mathrm{H}$ groups on its surface. The surface potential of the polymer increases when it forms amorphous calcium sulfate. The potential decreases when it forms amorphous calcium phosphate, revealing a constant negative value after forming apatite. The XPS and zeta potential analysis demonstrated that the surface potential of the polyethylene was highly negatively charged after soaking in SBF for $0.5 \mathrm{~h}$, increased for higher soaking times (up to $48 \mathrm{~h}$ ), and then decreased. The negative charge of the polymer at a soaking time of $0.5 \mathrm{~h}$ is attributed to the presence of $-\mathrm{SO}_{3} \mathrm{H}$ groups on the surface. The initial increase in the surface potential was attributed to the incorporation of positively charged calcium ions to form calcium sulfate, and then the subsequent decrease was assigned to the incorporation of negatively charged phosphate ions to form amorphous calcium phosphate, which eventually transformed into apatite. These results indicate that the formation of apatite on bioactive polyethylene in SBF is due to electrostatic interaction of the polymer surface and ions in the fluid.
\end{abstract}

\section{Introduction}

In the last few years, it has been demonstrated that several functional groups, such as $\mathrm{Si}-\mathrm{OH},{ }^{1} \mathrm{Ti}-\mathrm{OH},{ }^{2,3} \mathrm{Zr}-\mathrm{OH},{ }^{4,5} \mathrm{Ta}-$ $\mathrm{OH}^{6,7}$ and $\mathrm{Nb}-\mathrm{OH},{ }^{8}$ when incorporated into the surface of a biomaterial, can induce apatite formation on its surface, which proves that these groups effectively induce apatite nucleation.

It has been assumed that the complex process of apatite formation is due to the electrostatic interaction between the substrate surface and specific ions in the fluid. ${ }^{9}$

a3B's Research Group, Department of Polymer Engineering, University of Minho, Campus de Gualtar, 4710-057 Braga, Portugal.

E-mail: belinha@dep.uminho.pt

${ }^{b} I B B$ - Institute for Biotechnology and Bioengineering, PT Government Associated Laboratory, Braga, Portugal

${ }^{c}$ Department of Biomedical Sciences, College of Life and Health

Sciences, Chubu University, 1200 Matsumoto Kasugai, Aichi 487-8501,

Japan

${ }^{d}$ Department of Ceramic Engineering, School of Advanced Materials Engineering, Yonsei University, 134 Shinchon-dong, Seodaemun-gu, Seoul 120-749, Korea

${ }^{e}$ Ion Beam Engineering Experimental Laboratory, Graduate School of Engineering, Kyoto University, Nishikyo-ku, Kyoto 615-8510, Japan

${ }^{f}$ Department of Orthopaedic Surgery, Faculty of Medicine, Kyoto University, Sakyo-ku, Kyoto 606-8506, Japan

$\uparrow$ This paper is part of a Journal of Materials Chemistry theme issue on biomedical materials. Guest editor: Cameron Alexander.
Biomineralization, such as apatite formation, mainly occurs by calcium ion adsorption on and complexation with a negatively charged group of the artificial material and its subsequent complexation with phosphate ion. ${ }^{9}$ As result, amorphous calcium phosphate with low $\mathrm{Ca} / \mathrm{P}$ ratio will form, which is a metastable phase, and then will eventually transform into a stable apatite. ${ }^{10,11}$

Most of the above functional groups are speculated to reveal a negative charge to trigger electrostatic interaction with the calcium and phosphate ions in the fluid, and thereby to form the apatite crystal. ${ }^{10-12}$

Tanahashi and Matsuda ${ }^{9}$ demonstrated that a negatively charged surface group is effective for apatite nucleation. They found that the incorporation of $-\mathrm{PO}_{4} \mathrm{H}_{2}$ and $-\mathrm{COOH}$ groups on self-assembled monolayers (SAMs) is effective for apatite nucleation. On the other hand, positive charged surface groups like $-\mathrm{CONH}_{2},-\mathrm{OH},-\mathrm{NH}_{2}$ and $-\mathrm{CH}_{3}$ had weaker apatite nucleating ability. ${ }^{9}$

Additionally, Kim et al. ${ }^{13-15}$ confirmed these results by means of an electrophoresis study. They have shown that the surface potential of bioactive titanium is initially negative, indicating that the initialization of apatite nucleation involves an electrostatic interaction between the Ti-OH groups and calcium ions. Therefore, the functional groups that are able to become negatively charged at blood plasma $\mathrm{pH}(\approx 7.4$.) are 
assumed to be potentially effective for apatite nucleation in an in vivo environment.

In the same way, the process and kinetics of apatite formation on hydroxyapatite (HA) could be affected by bulk factors such as density and surface area as well as by surface factors such as composition and structure. Kim et al. ${ }^{16}$ investigated in terms of changes in surface composition and structure, and rationalized in terms of change in surface potential, the process and kinetics of apatite formation on HA. They confirmed that the process of apatite formation on HA sintered at high temperature was slow. The high sintering temperature leads to an initially lower negative surface charge of the HA and therefore leads to a surface which is deficient in hydroxyl and phosphate groups, which are responsible for the surface negativity.

Moreover, such factors might affect not the process, but the kinetics of the rate of apatite formation on the HA surface, through which the HA integrates with living bone.

Therefore, a detailed insight into the mechanism of apatite formation on bioactive ceramics is considered crucial for developing bioactive materials with enhanced or novel physical, chemical and biological functions. ${ }^{16}$ In previous studies, ${ }^{17-19}$ it was demonstrated that the incorporation of $-\mathrm{SO}_{3} \mathrm{H}$ groups onto polymeric surfaces could also serve as functional groups for apatite nucleation. However, it was speculated that the apatite forming ability induced by this functional group significantly depends on the $\mathrm{Ca}(\mathrm{OH})_{2}$ treatment. So, when the sulfonated samples are soaked in $\mathrm{Ca}(\mathrm{OH})_{2}$ saturated solution, it is expected that the $-\mathrm{SO}_{3} \mathrm{H}$ groups become negatively charged and interact with the positively charged $\mathrm{Ca}^{2+}$ ions from the $\mathrm{Ca}(\mathrm{OH})_{2}$ solution, which increase the apatite forming ability induced by this functional group.

To enhance the design of high-performance bioactive polymers, it is important to understand the mechanism of apatite formation on the polymer in vivo.

To clarify this mechanism, the main goal of this work is to evaluate the potential surface change of bioactive polyethylene as a function of immersion time in a simulated body fluid (SBF). The potential surface change is accompanied by a surface structural change, which was analysed by field-emission scanning electron microscopy (FE-SEM), energy-dispersive electron X-ray spectroscopy (EDS), thin film X-ray diffraction (TF-XRD) and X-ray photoelectron spectroscopy (XPS).

\section{Materials and methods}

\subsection{Specimen preparation}

In the present study, a high molecular weight polyethylene (HMWPE, Hostalen ${ }^{\circledR}$ GM 9255F, Hoechst, Germany) was used as substrate. HMWPE substrates were obtained by conventional injection moulding in a Klockner-Ferromatik Desma FM20 machine in order to produce plates. These plates were cut into substrate specimens of $15 \times 35 \times 3 \mathrm{~mm}^{3}$ size. The substrates were abraded with No. 400 diamond paste, ultrasonically washed with distilled water, and dried at $40{ }^{\circ} \mathrm{C}$ for $24 \mathrm{~h}$. These HMWPE substrates were prepared specifically for use in electrophoresis analyses after being subjected to sulfonation. Briefly, the substrates were soaked in $5 \mathrm{~mL}$ of $\mathrm{ClSO}_{3} \mathrm{H}(50 \mathrm{vol} \%)$ solution in Teflon ${ }^{\circledR}$ tubes and shaken at
120 strokes $\min ^{-1}$ for $10 \mathrm{~min}$ at $40{ }^{\circ} \mathrm{C}$. Further details on the sulfonation procedure can be found elsewhere. ${ }^{17,19}$

With the assumption that the calcium ions together with $-\mathrm{SO}_{3} \mathrm{H}$ groups might promote nucleation of apatite, the above sulfonated polymers were treated with calcium hydroxide $\left(\mathrm{Ca}(\mathrm{OH})_{2}\right)$ solution. Substrates after sulfonation were immediately soaked in $50 \mathrm{~mL}$ of saturated $(\sim 6.7 \mathrm{mM}) \mathrm{Ca}(\mathrm{OH})_{2}$ for 24 hours at $40{ }^{\circ} \mathrm{C}$, and washed with distilled water.

\subsection{Soaking in simulated body fluid (SBF)}

Sulfonated and $\mathrm{Ca}(\mathrm{OH})_{2}$-treated substrates were soaked in a simulated body fluid $(\mathrm{SBF})^{20}$ with ion concentrations $\left(\mathrm{Na}^{+}\right.$ 142.0, $\mathrm{K}^{+}$5.0, $\mathrm{Ca}^{2+} 2.5, \mathrm{Mg}^{2+} 1.5, \mathrm{Cl}^{-}$147.8, $\mathrm{HCO}_{3}{ }^{-}$4.2, $\mathrm{HPO}_{4}{ }^{2-} 1.0, \mathrm{SO}_{4}{ }^{2-} 0.5 \mathrm{mM}$ ) nearly equal to those of human blood plasma at $36.5^{\circ} \mathrm{C}$ for different periods up to $7 \mathrm{~d}$. The SBF was prepared by dissolving reagent-grade chemicals $\mathrm{NaCl}, \mathrm{NaHCO}_{3}, \mathrm{KCl}, \mathrm{K}_{2} \mathrm{PO}_{4} \cdot 3 \mathrm{H}_{2} \mathrm{O}, \mathrm{MgCl}_{2} \cdot 6 \mathrm{H}_{2} \mathrm{O}, \mathrm{CaCl}_{2}$ and $\mathrm{NaSO}_{4}$ into distilled water, and buffered at $\mathrm{pH} 7.40$ with tris(hydroxymethyl)aminomethane $\left(\left(\mathrm{CH}_{2} \mathrm{OH}\right)_{3} \mathrm{CNH}_{3}\right)$ and $1 \mathrm{M}$ hydrochloric acid at $36.5{ }^{\circ} \mathrm{C}$. After soaking, the substrates were removed from the SBF, washed with distilled water and dried in a clean bench oven.

\subsection{Surface potential analyses of the specimens}

After the polymer substrates had been soaked in SBF for various periods of time, the substrates were removed from the solution and washed with distilled water. Then, the substrate was immediately soaked again in fresh SBF, which was dispersed with monitor particles of polystyrene latex in a high-purity silica glass cell. This glass cell was connected into a laser electrophoresis spectroscope (Model ELS9000K, Otsuka Electronic Co., Osaka, Japan) to measure the zeta potential of the substrate surface. This system adopts laser Doppler electrophoresis to measure the electrophoretic mobility of the monitored particle, whose surface charge is defined as 0 . The zeta potential $(\zeta)$ of specimen substrates is given by the Smoluchowski equation,

$$
\zeta=4 \pi \eta U / \varepsilon
$$

where $U$ is the electrophoretic mobility of monitor particle, $\eta$ is the viscosity of solution, and $\varepsilon$ is the dielectric constant of the solution. As long as the monitored particles are floating in the solution, the electrophoretic mobility $(U)$ depends not on the size and shape of the particles, but solely on the electroosmosis current in terms of the surface charge of the specimen substrate in solution. ${ }^{21}$

\subsection{Analyses of the surface and SBF}

After each given soaking period, the above analysis of zeta potential was complemented by field-emission scanning electron microscopy (FE-SEM: S-4700, Hitachi Ltd., Japan), energy-dispersive electron X-ray spectroscopy (EDS: Bruker AXS Microanalysis GmbH, Quantax 400, Germany), thin film X-ray diffraction (TF-XRD: RINT2500, Rigaku Co., Japan) and X-ray photoelectron spectroscopy (XPS: ESCA-3200, Shimadzu Co., Japan) of the surface of the polymer substrate before and after soaking in SBF. In the XPS measurements, $\mathrm{Mg}-\mathrm{K} \alpha(1253.6 \mathrm{eV})$ radiation was used as the $\mathrm{X}$-ray source. 
The binding energy (BE) scale was calibrated determining the $\mathrm{BE}$ of the $\mathrm{Ag}_{3 \mathrm{~d}_{5 / 2}}(368.2 \mathrm{eV})$ level using a spectroscopically pure silver standard and the energy values were measured with an accuracy of $\pm 0.2 \mathrm{eV}$. For analysis, specimens were attached with carbon tape to tin holders and placed into an analysis chamber at high vacuum for $24 \mathrm{~h}$ prior to study. Also, due to the surface charging, the peak shift was corrected using the $\mathrm{C}_{1 \mathrm{~s}}$ level at $285.0 \mathrm{eV}$ as an internal standard. Since the sulfonated polymer substrates might degrade upon exposure to X-rays, all spectra were recorded using a low power source and a pass energy of $50 \mathrm{eV}$. The recording time for each spectrum was also kept to a minimum to avoid radiation-induced damage. ${ }^{22}$ All recorded XPS spectra were deconvoluted in several signals that were assumed to have a Gaussian line shape and were resolved into individual components after proper subtraction of base line using the Shirley background subtraction method.

The element concentrations of the SBF, before and after soaking of the polymer substrates, were measured using inductively coupled plasma atomic emission spectrometry (ICP: SPS-1500VR, Seiko Instruments Inc., Japan).

\section{Results}

\subsection{TF-XRD, FE-SEM and EDS analysis}

In previous work, ${ }^{19}$ it was demonstrated the sulfonated and $\mathrm{Ca}(\mathrm{OH})_{2}$-treated HMWPE samples can induce the formation of an apatite layer. For this particular study, the surface potentials of sulfonated HMWPE samples and sulfonated and $\mathrm{Ca}(\mathrm{OH})_{2}$-treated HMWPE samples were studied in detail, to demonstrate that formation of an apatite layer on bioactive polyethylene in $\mathrm{SBF}$ is due to electrostatic interaction of the polymer surface and ions in the SBF solution. Therefore, to complement the zeta potential studies, TF-XRD and FE-SEM analysis were used to confirm the formation of an apatite layer. In addition, EDS analysis was used to calculate the $\mathrm{Ca} / \mathrm{P}$ atomic ratio of the apatite formed on sulfonated and $\mathrm{Ca}(\mathrm{OH})_{2}-$ treated HMWPE samples.

Fig. 1 shows the TF-XRD patterns of the surfaces of HMWPE polymers, which were subjected to sulfonation treatment, subsequent $\mathrm{Ca}(\mathrm{OH})_{2}$ treatment, and those subjected to soaking in SBF for $168 \mathrm{~h}$ after sulfonation treatment, and those subjected to soaking in SBF for several periods of time after sulfonation and the $\mathrm{Ca}(\mathrm{OH})_{2}$ treatments as demonstrated in previous work. ${ }^{19}$

Once more, we can demonstrate in this work that specimens soaked in SBF just after sulfonation are not able to induce apatite nucleation (see Fig. 1A). This fact points to a significant dependence of $\mathrm{Ca}(\mathrm{OH})_{2}$ treatment on the apatiteforming ability in the $\mathrm{SBF}$ of the $-\mathrm{SO}_{3} \mathrm{H}$ groups deposited on polymer specimens, as confirmed in previous work. ${ }^{19}$

It can be observed that the structure of HMWPE remains unaltered after sulfonation, showing the same reflections observed for the untreated specimen even after immersion in the calcium hydroxide solution.

In Fig. 1B it can be seen that after soaking in SBF for $72 \mathrm{~h}$, using non-immersed samples as controls, the TF-XRD pattern of the surface of the HMWPE specimen exhibit two broad diffraction peaks, the positions and intensities of which can assigned to an apatite-like phase (ASTM JCPDS 9-432). The
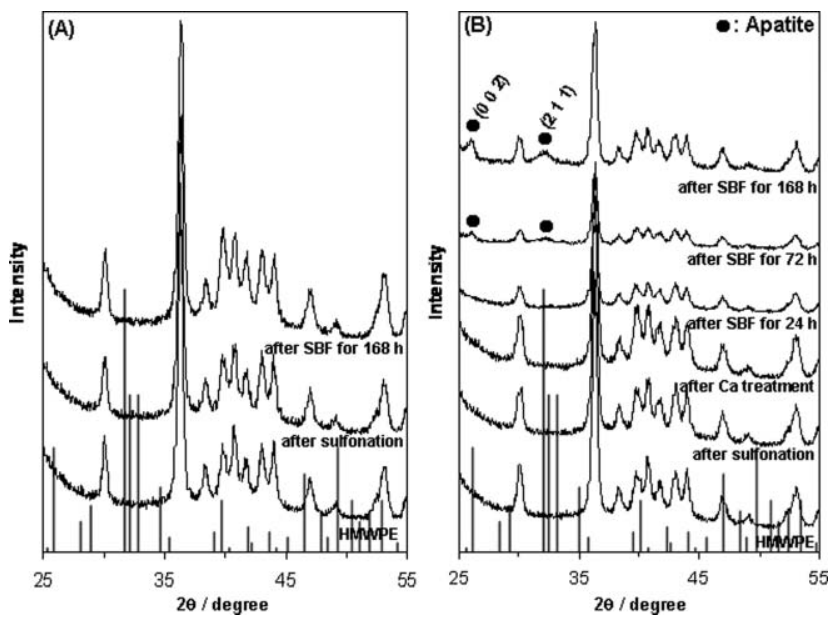

Fig. 1 TF-XRD patterns of the surfaces of HMWPE, which were subjected to soaking in $\mathrm{SBF}$ for $7 \mathrm{~d}$ after sulfonation treatment (A), and to soaking in SBF for various periods of time after sulfonation and $\mathrm{Ca}(\mathrm{OH})_{2}$ treatments (B).

peaks at $25.87^{\circ}$ and $31.78^{\circ}$ in $2 \theta$ correspond to the $\left(\begin{array}{lll}0 & 0 & 2\end{array}\right)$ and (2 $\left.\begin{array}{lll}2 & 1 & 1\end{array}\right)$ diffraction planes of apatite, respectively. The intensity of these diffraction planes increases as the soaking time in SBF increases (see Fig. 1B).

In Fig. 2 are shown the FE-SEM images of the HMWPE specimens before and after sulfonation, $\mathrm{Ca}(\mathrm{OH})_{2}$ treatment and subsequent soaking in SBF for several periods of time. It is worth noting that after the sulfonation procedure there were no signals of any eventual degradation of the polymer as is shown in Fig. 2. This feature confirms that proposed sulfonation reactions just transform the chemical composition and structure of the outer surface layer, the substrate bulk properties remaining unaltered as demonstrated in previous work. $^{19}$

It can be seen in Fig. 2 that after immersion in SBF, a uniform calcium phosphate layer is formed on the substrate after only $48 \mathrm{~h}$ of immersion in $\mathrm{SBF}$. The $\mathrm{Ca} / \mathrm{P}$ atomic ratio of this layer was 1.43 , much lower than the value of 1.67 of hydroxyapatite. After $72 \mathrm{~h}$, the polymeric sample was covered with a dense and compact apatite layer confirmed by the TF-XRD analysis (see Fig. 1B) and demonstrated in previous work. ${ }^{19}$ Moreover, at higher magnifications a finer structure is evidenced where needle-like crystals are agglomerated. The apatite has a $\mathrm{Ca} / \mathrm{P}$ ratio of 1.58 and as the soaking time increase the $\mathrm{Ca} / \mathrm{P}$ ratio increased up to 1.62 , which is slightly lower than that of stoichiometric hydroxyapatite (see Fig. 2).

\subsection{Zeta potential measurements}

To prove that the formation of apatite on bioactive polyethylene in SBF is due to electrostatic interaction of the polymer surface and ions present in the SBF solution, a laser electrophoresis zeta potential analyzer was used.

Fig. 3 shows the variation of zeta potential of the surface of the HMWPE specimens as a function of soaking time in SBF. For HMWPE that was subjected to sulfonation and subsequent soaking in SBF for several periods of time, the zeta potential was $-38 \mathrm{mV}$ immediately after immersion (see 

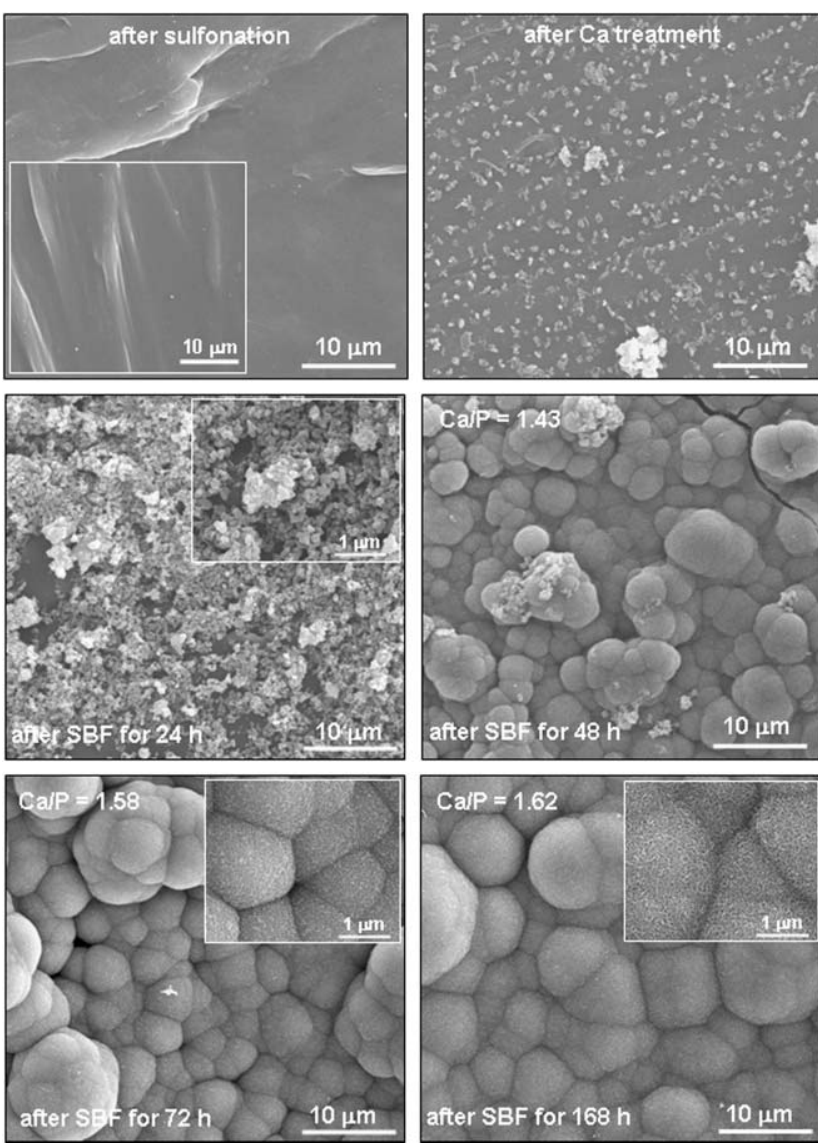

Fig. 2 SEM photographs of the surfaces of HMWPE, which were subjected to the sulfonation treatment and the subsequent $\mathrm{Ca}(\mathrm{OH})_{2}$ treatment and then immersed in the SBF for various periods of time.

Fig. 3A). After soaking in $\mathrm{SBF}$ for $0.5 \mathrm{~h}$, there was a slight increase to -32 . Then, the zeta potential increased with increasing soaking time, reaching a maximum negative value of $-20 \mathrm{mV}$ after $48 \mathrm{~h}$. This increase is attributed to the incorporation of positively charged calcium ions from SBF solution. Afterwards, it decreased with further soaking time, revealing always a negative value as is shown in Fig. 3A.

The zeta potential of the HMWPE surface that was subjected to sulfonation and calcium treatment was $-24 \mathrm{mV}$ just after $0.5 \mathrm{~h}$ in $\mathrm{SBF}$, which was higher than that of the HMWPE that was only subjected to sulfonation (see Fig. 3B). Such a result is due to the immersion of sulfonated samples in the $\mathrm{Ca}(\mathrm{OH})_{2}$ saturated solution, which leads to the incorporation of $\mathrm{Ca}$ ions. Until $24 \mathrm{~h}$, there is an increased in the zeta potential to $-17 \mathrm{mV}$. Then, the zeta potential increased with increasing soaking time, reaching a maximum positive value of $9 \mathrm{mV}$ after $48 \mathrm{~h}$ as is shown in Fig. 3B. It decreased with further soaking time, revealing a negative value after $72 \mathrm{~h}$. After $168 \mathrm{~h}$, the zeta potential converged finally to a constant negative value (see Fig. 3B).

\subsection{XPS measurements}

Fig. 4 shows the $\mathrm{C}_{1 \mathrm{~s}}$ and $\mathrm{O}_{1 \mathrm{~s}}$ core-level XPS spectra of HWMPE after sulfonation and $\mathrm{Ca}(\mathrm{OH})_{2}$ treatments, as a function of soaking time in SBF.
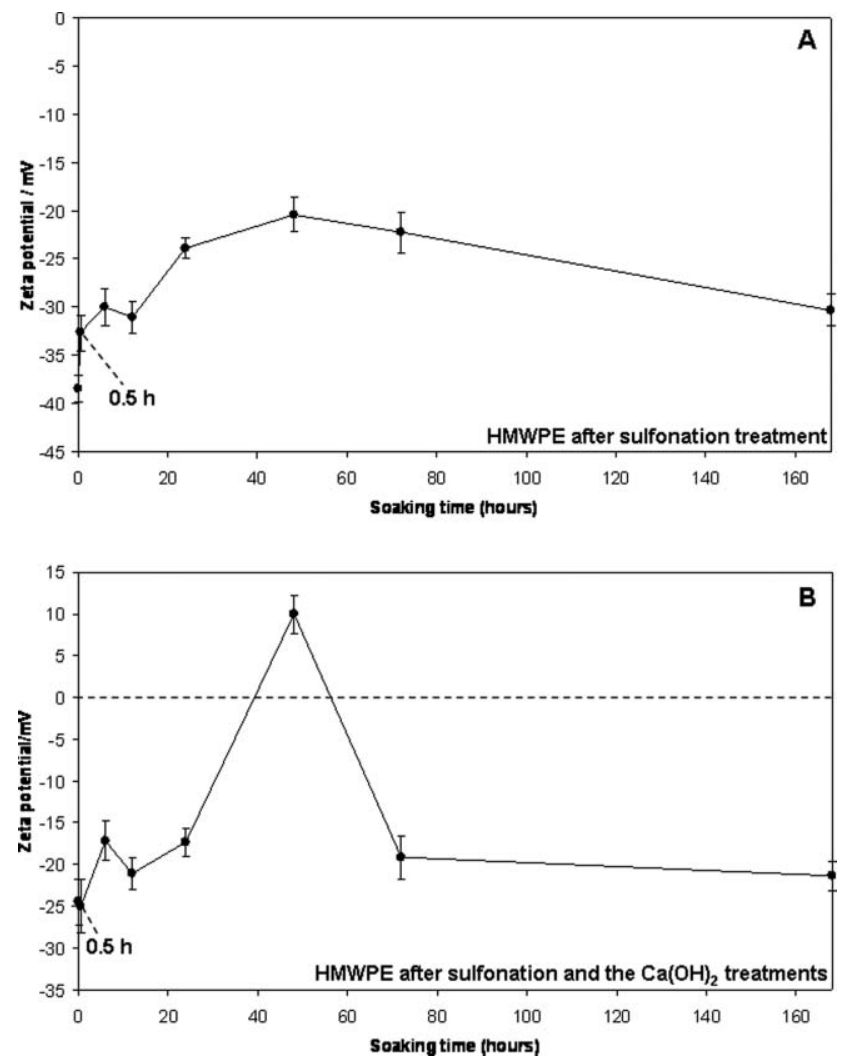

Fig. 3 Zeta potentials of the sulfonation-treated HMWPE (A) and of the sulfonation- and $\mathrm{Ca}(\mathrm{OH})_{2}$-treated HMWPE (B) as a function of soaking time in SBF.

As can be seen in Fig. 4, the $\mathrm{C}_{1 \mathrm{~s}}$ core-level XPS spectra for HMWPE after sulfonation and $\mathrm{Ca}(\mathrm{OH})_{2}$ treatment contain three main components at $285.0 \mathrm{eV}$ and at about $284.5 \mathrm{eV}$, which were assigned to the main carbon backbone, and around $286 \mathrm{eV}$ for oxygen bonded carbons. The appearance of the last component can be attributed to the increase in the oxygen surface content due to the performed sulfonation. After $6 \mathrm{~h}$, the intensities of the $\mathrm{C}-\mathrm{C}$ and $\mathrm{C}-\mathrm{H}$ peaks decrease dramatically and the peak at $284.5 \mathrm{eV}$ almost disappears due the formation of calcium sulfate $\left(\mathrm{CaSO}_{4} \cdot 2 \mathrm{H}_{2} \mathrm{O}\right)$. However, the main component of the $\mathrm{C}_{1 \mathrm{~s}}$ signal remains centred at $285.0 \mathrm{eV}$ together with small contributions at higher binding energies attributed to oxidized carbon functional groups. The reduction of the carbon signal in XPS spectra is even larger in spectra recorded after a soaking period of $48 \mathrm{~h}$ in SBF, and the reason for this is the deposition of the apatite layer, which was confirmed by TF-XRD and SEM measurements and in previous work. ${ }^{19}$ Moreover, with increasing soaking time an increase in the intensities of the bands assigned to $\mathrm{C}-\mathrm{O}$ bonds can be seen, compared to those for the main carbon backbone.

In the $\mathrm{O}_{1 \mathrm{~s}}$ core-level spectra a clear $\mathrm{O}_{1 \mathrm{~s}}$ peak at $532.51 \mathrm{eV}$ can be observed, ascribed to the $\mathrm{O}-\mathrm{S}$ bond due to the sulfonation (see Fig. 4). This signal together with the $\mathrm{C}-\mathrm{O}$ signal in the $\mathrm{C}_{1 \mathrm{~s}}$ core-level spectra may involve the existence of a chemical bond between the polymer surface and the $-\mathrm{SO}_{3} \mathrm{H}$ groups deposited on the substrates after soaking in the $\mathrm{ClSO}_{3} \mathrm{H}$ solution. No chlorine signal is detected in the XPS spectra for HMWPE samples after this treatment. This fact 

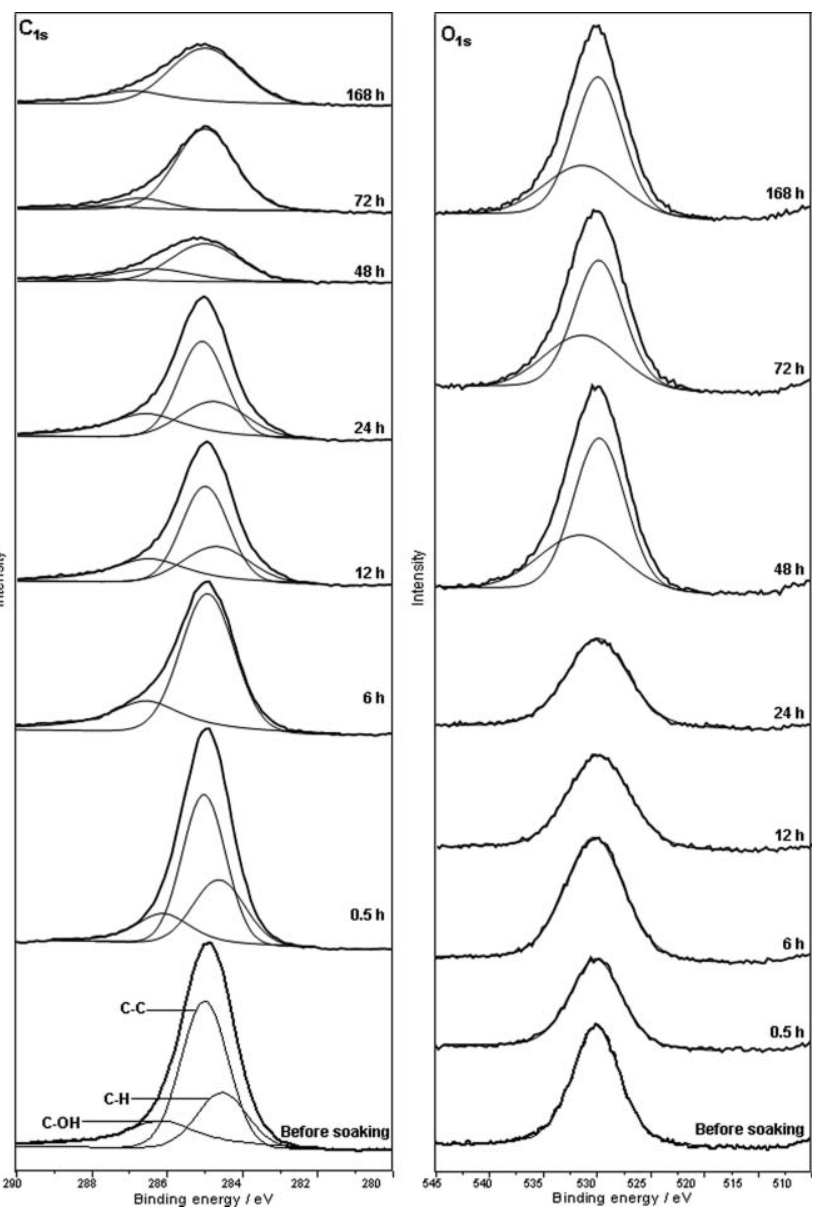

Fig. $4 \mathrm{C}_{1 \mathrm{~s}}$ and $\mathrm{O}_{1 \mathrm{~s}}$ XPS spectra of the surface of HMWPE after being subjected to sulfonation and $\mathrm{Ca}(\mathrm{OH})_{2}$ treatments as a function of soaking time in SBF.

confirms that the sulfonation proposed in the present work avoids side reactions where chlorine ions could be incorporated into the material surface during the process. Up to $24 \mathrm{~h}$ in SBF, the binding energy of the main peak ascribed to the $\mathrm{Ca}-\mathrm{O}$ bond hardly changed due to the nucleation of poorly crystalline $\mathrm{CaSO}_{4} \cdot 2 \mathrm{H}_{2} \mathrm{O}$. After a soaking period of $48 \mathrm{~h}$, the binding energy of the main $\mathrm{O}_{1 \mathrm{~s}}$ peak shifted to higher energies. In addition, it is worth noting the formation of a secondary signal at lower binding energies $(531.8 \mathrm{eV})$ ascribed to double bonded oxygen $(\mathrm{O}=\mathrm{P}-\mathrm{OH})$. Furthermore, this signal reaches a maximum which can be attributed to the contribution of carbonate groups in the structure of apatite deposited on the material surface. These results are in agreement with those obtained from $\mathrm{C}_{1 \mathrm{~s}}$ spectra (see Fig. 4).

Fig. 5 shows the $\mathrm{Ca}_{2 p}$ and $\mathrm{P}_{2 p}$ XPS spectra of the surface of HWMPE after sulfonation and $\mathrm{Ca}(\mathrm{OH})_{2}$ treatments, as a function of soaking time in SBF.

As can be seen in Fig. 5, in the $\mathrm{Ca}_{2 p}$ core-level spectra, the $\mathrm{Ca}_{2 \mathrm{p}}$ peak was first detected before soaking in SBF, which was due to the incorporation of $\mathrm{Ca}$ ions from the $\mathrm{Ca}(\mathrm{OH})_{2}$ treatment. Its intensity remained low up to a soaking period of $6 \mathrm{~h}$. An increase of the $\mathrm{Ca}_{2 p}$ peak intensity was observed after $6 \mathrm{~h}$ in $\mathrm{SBF}$, due to the formation of $\mathrm{CaSO}_{4} \cdot 2 \mathrm{H}_{2} \mathrm{O}$ film. These results are in good agreement with those obtained
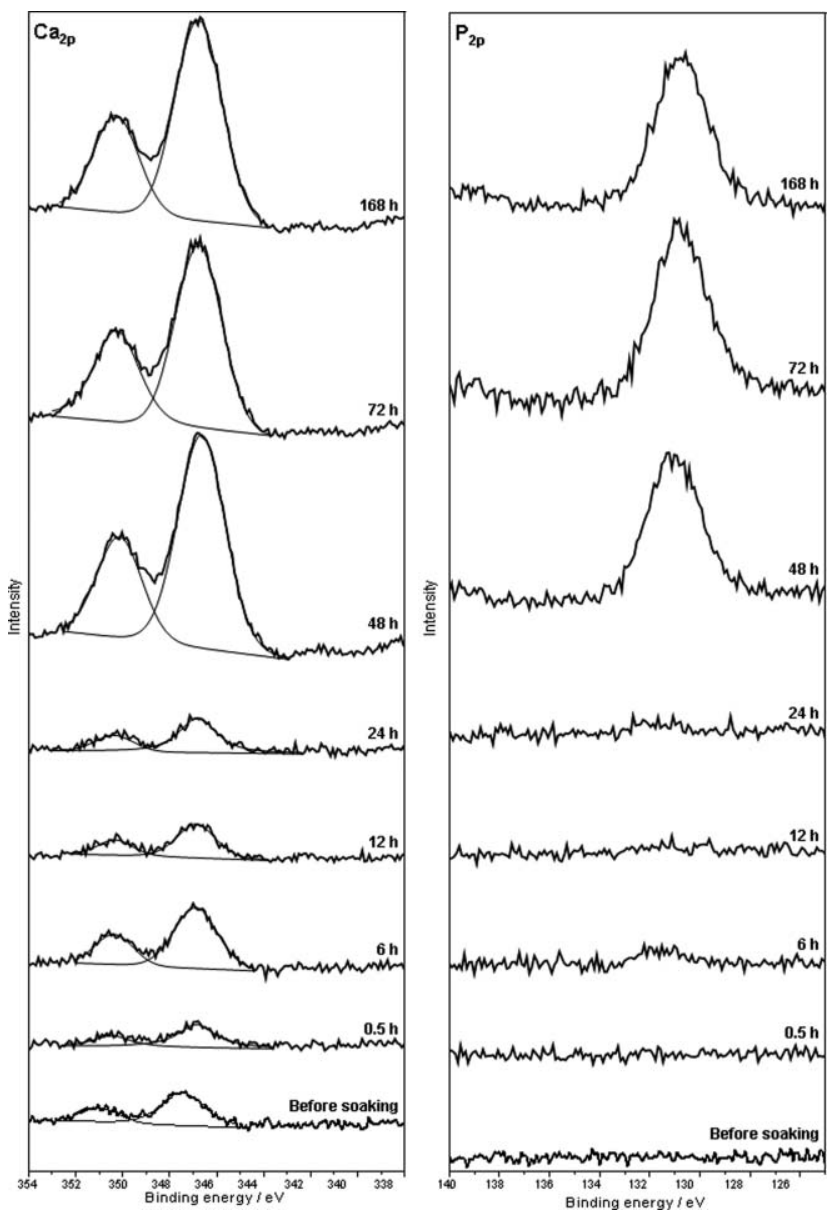

Fig. $5 \mathrm{Ca}_{2 p}$ and $\mathrm{P}_{2 \mathrm{p}}$ XPS spectra of the surface of HMWPE after being subjected to sulfonation and $\mathrm{Ca}(\mathrm{OH})_{2}$ treatments as a function of soaking time in SBF.

for $\mathrm{O}_{1 \mathrm{~s}}$ XPS spectra. After $48 \mathrm{~h}$, the intensities of these peaks increased abruptly, and their binding energies shifted to slightly higher positions. Their intensities increase gradually up to $168 \mathrm{~h}$.

In the $\mathrm{P}_{2 \mathrm{p}}$ core-level spectra, a clear $\mathrm{P}_{2 \mathrm{p}}$ peak at $131.5 \mathrm{eV}$ can be observed after a soaking period of only $48 \mathrm{~h}$, which is assigned to $\mathrm{P}-\mathrm{O}$ bonds in the phosphate groups. ${ }^{23}$ After $72 \mathrm{~h}$, the intensity of the $P_{2 p}$ peak increased gradually up to $168 \mathrm{~h}$.

In the $S_{2 p}$ core-level spectra (data not shown), sulfur is detected in spectra of sulfonated materials as a broad band. The signal can be deconvoluted into two components centred at 169.3 and $169.4 \mathrm{eV}$ and assigned to the $\mathrm{S}_{2 \mathrm{p} 3 / 2}$ and $\mathrm{S}_{2 \mathrm{p} 1 / 2}$ components for $\mathrm{S}-\mathrm{O}$ bonds in a sulfate environment. After the subsequent calcium hydroxide treatment and immersion in SBF for several periods, the $S_{2 p}$ peak is not longer detected in the XPS spectra, due to the formation of a very thin calcium sulfate layer covered with apatite as confirmed in $\mathrm{O}_{1 \mathrm{~s}}$ and $\mathrm{Ca}_{2 p}$ XPS spectra.

\subsection{ICP analysis}

By ICP analysis (data not shown) and as confirmed in previous work ${ }^{19}$ no significant change in the concentration of $\mathrm{Ca}$ and $\mathrm{P}$ elements was observed for the sulfonated samples without $\mathrm{Ca}$ ions. 
As for the sulfonated samples with $\mathrm{Ca}$ ions, after $6 \mathrm{~h}$ in SBF there was a decrease of $\mathrm{Ca}$ in $\mathrm{SBF}$, which may be due to the formation of calcium sulfate film. Then, after $24 \mathrm{~h}$, there was a slight increase in the amount of $\mathrm{Ca}$ in the $\mathrm{SBF}$, which is attributed to the release of $\mathrm{Ca}^{2+}$ ions from the surface to the solution. Then, as the soaking time increases, $\mathrm{Ca}$ and $\mathrm{P}$ concentrations decreased gradually due to apatite formation by consuming the calcium and phosphate ions in SBF.

\section{Discussion}

In previous work, ${ }^{19}$ it was demonstrated that the incorporation of $-\mathrm{SO}_{3} \mathrm{H}$ groups onto the surface of HMWPE through sulfonation and stabilization by soaking in a calcium hydroxide saturated solution was able to form a dense and uniform apatite layer after soaking for up to seven days in simulated body fluid. To reveal the reasons why this complex process is required for apatite formation and to enhance the design of high-performance bioactive polymers, a detailed study was achieved by measuring the zeta potential of the surface of HMWPE, after sulfonation and subsequent soaking in a $\mathrm{Ca}(\mathrm{OH})_{2}$ saturated solution, by laser electrophoresis for different periods of time in SBF solution.

The zeta potentials of the surfaces of bioactive and nonbioactive polyethylene were changed drastically when the polymers were soaked in SBF as shown in Fig. 3A and B. In the case of HMWPE that was subjected to sulfonation and thesubsequent soaking in SBF for several periods of time, the zeta potential did not change significantly up to $168 \mathrm{~h}$ (see Fig. 3A). Once more, these results confirm that the apatite forming ability induced by the $-\mathrm{SO}_{3} \mathrm{H}$ groups, incorporated onto the polymer, is weaker. These results are in agreement with those obtained from TF-XRD (see Fig. 1A). When the
HMWPE was subjected to sulfonation and $\mathrm{Ca}(\mathrm{OH})_{2}$ treatment, the zeta potential was highly negative at the end of the initial soaking period of $0.5 \mathrm{~h}$. Then, it increased to reveal a maximum positive value with increasing soaking time up to $48 \mathrm{~h}$, after which it decreased to a constant negative value with further soaking time up to $168 \mathrm{~h}$ as is shown in Fig. 3B. The TF-XRD, FE-SEM and EDS results indicate that the surface of this bioactive polyethylene formed amorphous calcium sulfate within $24 \mathrm{~h}$, amorphous calcium phosphate with a $\mathrm{Ca} / \mathrm{P}$ ratio of 1.43 within $48 \mathrm{~h}$, and apatite had formed within $72 \mathrm{~h}$ with a $\mathrm{Ca} / \mathrm{P}$ ratio of 1.58 , which was detected by TF-XRD. Then, the $\mathrm{Ca} / \mathrm{P}$ ratio increased to 1.62 in the soaking period of 72-168 h.

Complementing the zeta potential results with XPS results, the bioactivity of this polyethylene can be explained by the following mechanism: the release of the $\mathrm{Ca}^{2+}$ ions into the surrounding fluid, which were incorporated during the calcium treatment, led to the formation of $-\mathrm{SO}_{3} \mathrm{H}$ groups, after $0.5 \mathrm{~h}$ soaking in SBF (see Fig. 4 and 5). It is thought that these $-\mathrm{SO}_{3} \mathrm{H}$ groups are the source of the negative charge of the HMWPE at the soaking time of $0.5 \mathrm{~h}$ (see Fig. 3B). The $-\mathrm{SO}_{3} \mathrm{H}$ groups immediately interact with the calcium ions in the fluid to form calcium sulfate after $24 \mathrm{~h}$ in SBF (see Fig. 5). The calcium sulfate incorporates the phosphate ions, as well as the calcium ions, in the fluid to form amorphous calcium phosphate from about $48 \mathrm{~h}$ immersion time in SBF (see Fig. 4 and 5). At the soaking time of $72 \mathrm{~h}$, crystalline apatite is first detected by the TF-XRD patterns on the surface of HMWPE polymer (see Fig. 1B). Once apatite nuclei are formed, they can spontaneously grow into a uniform layer by consuming calcium and phosphate ions from the $\mathrm{SBF}{ }^{24}$

In Fig. 6 is shown a schematic drawing of this process of apatite formation on sulfonated and $\mathrm{Ca}(\mathrm{OH})_{2}$-treated HMWPE samples in SBF.
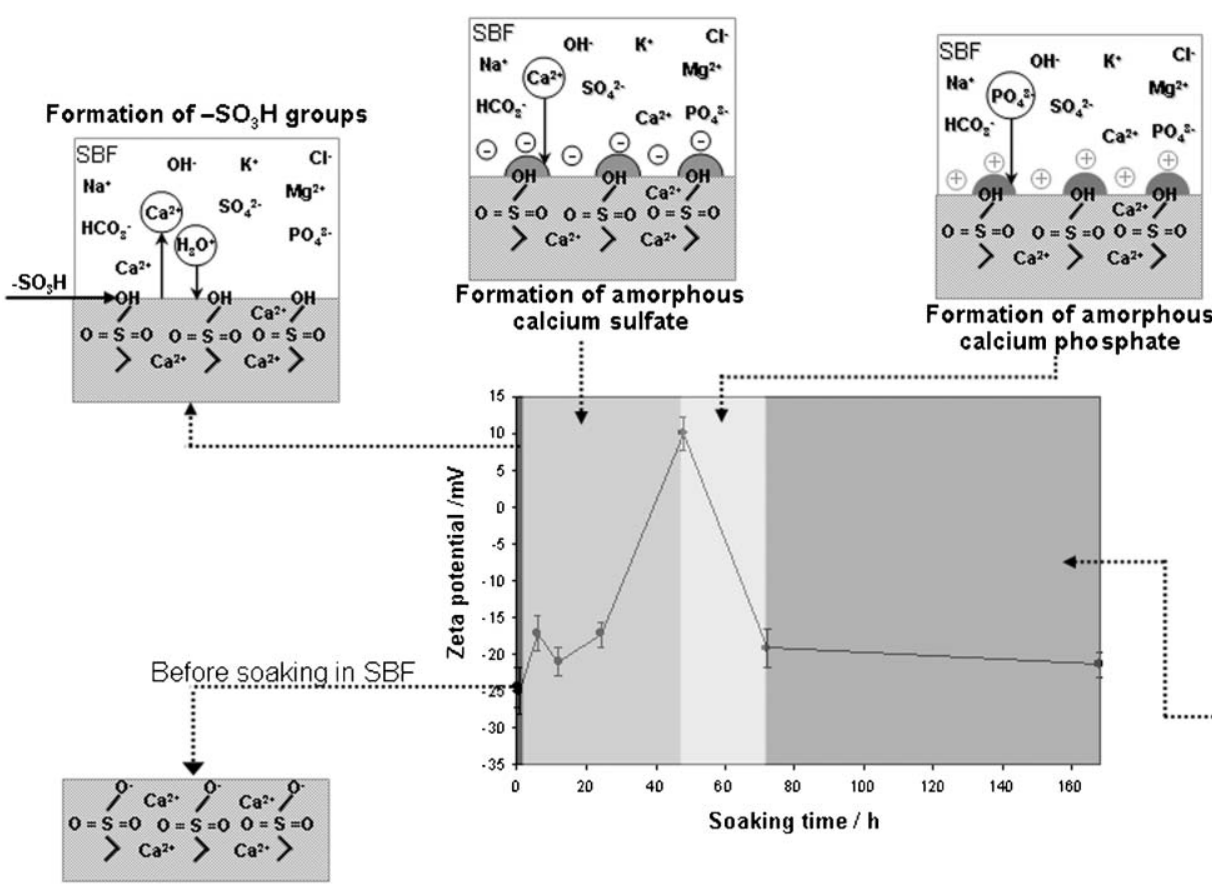
calcium phosphate
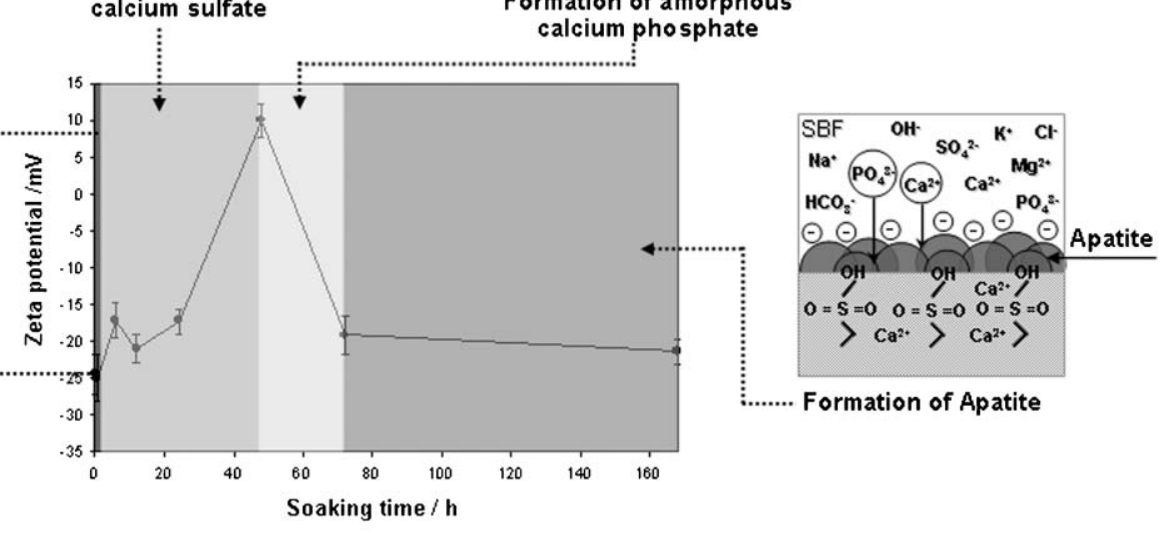

Fig. 6 Schematic showing the relationship between the changes in the surface structure and the potential of the incorporation of $-\mathrm{SO}_{3} \mathrm{H}$ groups into HWMPE in the apatite formation process on its surface in SBF. 
Immediately after immersion in SBF, there was the release of $\mathrm{Ca}^{2+}$ into the surrounding fluid, which was incorporated during the calcium treatment, and leads to the formation of $-\mathrm{SO}_{3} \mathrm{H}$ groups, after $0.5 \mathrm{~h}$ soaking in $\mathrm{SBF}$. It is thought that these $-\mathrm{SO}_{3} \mathrm{H}$ groups are the source of the negative charge of the HMWPE at the soaking time of $0.5 \mathrm{~h}$. The increase in the zeta potential from $24 \mathrm{~h}$ to $48 \mathrm{~h}$ is attributed to the incorporation of positively charged $\mathrm{Ca}^{2+}$ ions present in the fluid by the negatively charged $-\mathrm{SO}_{3} \mathrm{H}$ groups, through which an amorphous calcium sulfate layer is formed on the substrate. The subsequent decrease of the zeta potential from $48 \mathrm{~h}$ to $72 \mathrm{~h}$ is attributed to the incorporation of negatively charged phosphate ions in the fluid by the positively charged calcium sulfate, through which amorphous calcium phosphate is formed on the polymeric substrate. This calcium phosphate is transformed eventually into negatively charged apatite after $72 \mathrm{~h}$ due to hydroxyl and phosphate groups on its surface. As the soaking time increase the zeta potential decreases, revealing a constant negative value after forming the apatite layer. This spontaneous transformation into crystalline apatite is due to the lower solubility of hydroxyapatite in water than any other calcium phosphate, i.e., it is the most stable form of calcium phosphate in aqueous media around $\mathrm{pH} 7.40 .^{25}$

Furthermore, hydroxyapatite is known to reveal a negative charge in the in vivo environment because of the hydroxyl and phosphate groups on its surface. ${ }^{26}$

\section{Conclusions}

The mechanism of apatite formation on bioactive polyethylene in SBF is due to electrostatic interaction of the polymer surface and ions in the fluid which progresses in the following way: (1) formation of $-\mathrm{SO}_{3} \mathrm{H}$ groups with a negative charge by the $\mathrm{Ca}^{2+}$ ions release from the HMWPE sample; (2) formation of an amorphous calcium sulfate with a positive charge by combination of negatively charged $-\mathrm{SO}_{3} \mathrm{H}$ with the positively charged $\mathrm{Ca}^{2+}$ ions in the SBF; (3) formation of an amorphous calcium phosphate by combination of the positively charged calcium sulfate with the negatively charged phosphate ions in the SBF; and (4) formation of the apatite with a negative charge by transformation of the calcium phosphate into crystalline apatite. This study indicates that by using laser electrophoresis zeta-potential analyzer it is possible to understand the mechanism of apatite formation on bioactive polyethylene as a function of immersion time in a SBF. Moreover, this technique can be very useful to improve the design of high-performance bioactive polymers.

\section{Acknowledgements}

I. B. Leonor thanks the Portuguese Foundation for Science and Technology for providing her a PhD scholarship (SFRH/ BD/9031/2002). This work was partially supported by FCT Foundation for Science and Technology, through funds from the POCTI and/or FEDER programmes. The authors thank Prof. M. Takaoka from the Dept. of Urban \& Environmental Engineering, Graduate School of Engineering, Kyoto
University, Japan for the XPS analysis. This research work is dedicated to Prof. Hyun-Min Kim, who gave valuable support and encouragement during I. B. Leonor's stay in Kyoto University.

\section{References}

1 P. Li, C. Ohtsuki, T. Kokubo, K. Nakanishi, N. Soga, T. Nakamura and T. Yamamuro, J. Appl. Biomater., 1993, 4, 221-229.

2 H. M. Kim, F. Miyaji, T. Kokubo and T. Nakamura, J. Biomed Mater. Res., 1996, 32, 409-417.

3 T. Kokubo, F. Miyaji, H. M. Kim and T. Nakamura, J. Am. Ceram. Soc., 1996, 79, 1127-1129.

4 M. Uchida, H. M. Kim, T. Kokubo, F. Miyaji and T. Nakamura, J. Am. Ceram. Soc., 2001, 84, 2041-2044.

5 M. Uchida, H. M. Kim, T. Kokubo, M. Nawa, T. Asano, K. Tanaka and T. Nakamura, J. Biomed. Mater. Res., 2002, 60, 277-282.

6 T. Miyazaki, H. Kim, T. Kokubo, H. Kato and T. Nakamura, J. Sol-Gel Sci. Technol., 2001, 21, 83-88.

7 T. Miyazaki, H.-M. Kim, T. Kokubo, C. Ohtsuki, H. Kato and T. Nakamura, Biomaterials, 2002, 23, 827.

8 T. Miyazaki, H. Kim, T. Kokubo, C. Ohtsuki and T. Nakamura, J. Ceram. Soc. Jpn., 2001, 109, 929-933.

9 M. Tanahashi and T. Matsuda, J. Biomed. Mater. Res., 1997, 34, 305-315.

10 T. Kokubo, H. M. Kim and M. Kawashita, Biomaterials, 2003, 24, 2161-2175.

11 T. Kokubo, H. M. Kim, M. Kawashita and T. Nakamura, J. Mater. Sci.: Mater. Med., 2004, 15, 99-107.

12 H. Kim, Curr. Opin. Solid State Mater. Sci., 2003, 7, 289-299.

13 T. Himeno, M. Kawashita, H.-M. Kim, T. Kokubo and T. Nakamura, in Bioceramics Vol. 14, ed. S. Brown, I. R. Clarke and P. Williams, Trans Tech Publications, Switzerland, 2001, pp. 641-644.

14 T. Himeno, H.-M. Kim, H. Kaneko, M. Kawashita, T. Kokubo and T. Nakamura, in Bioceramics Vol. 15, ed. B. Ben-Nissan, D. Sher and W. Walsh, Trans Tech Publications, Switzerland, 2002, pp. 457-460.

15 H. M. Kim, T. Himeno, M. Kawashita, J. H. Lee, T. Kokubo and T. Nakamura, J. Biomed. Mater. Res., A, 2003, 67, 1305-1309.

16 H. M. Kim, T. Himeno, T. Kokubo and T. Nakamura, Biomaterials, 2005, 26, 4366-4373.

17 I. B. Leonor, F. Balas, H.-M. Kim, T. Kokubo and R. L. Reis, 18th Meeting of the European Society For Biomaterials, Stuttgart, Germany, 2003, T027.

18 I. B. Leonor, F. Balas, H.-M. Kim, T. Kokubo and R. L. Reis, 29th Annual Meeting of the Society For Biomaterials, Reno, Nevada, USA, 2003, p. 387.

19 I. B. Leonor, H.-M. Kim, F. Balas, M. Kawashita, T. Kokubo, R. L. Reis and T. Nakamura, J. Mater. Sci.: Mater. Med., 2007, in press.

20 T. Kokubo, H. Kushitani, S. Sakka, T. Kitsugi and T. Yamamuro, J. Biomed. Mater. Res., 1990, 24, 721-734.

21 T. G. M. Van De Ven, Colloidal Hydrodynamics, Academic Press, New York, 1989.

22 G. Beamson and D. Briggs, High Resolution XPS of organic polymers: the Scientia ESCA300 database, John Wiley and Sons, Chichester, 1992.

23 N. Ikeo, Y. Iijima, N. Nimura, M. Sigematsu, T. Tazawa, S. Matsumoto, K. Kojima and Y. Nagasawa, JEOL Handbook for X-Ray Photoelectron Spectroscopy, JEOL Publishing, Tokyo, 1992.

24 H.-M. Kim, J. Ceram. Soc. Jpn., 2001, 109, S49-S57.

25 M. Tung, in Calcium phosphate in biological and industrial system, ed. Z. Amjad, Kluwer Academic Publishers, Dordrecht, 1998, pp. $1-19$.

26 P. Somasundaran and B. Markovic, in Calcium phosphate in biological and industrial system, ed. Z. Amjad, Kluwer Academic Publishers, Dordrecht, MA, 1998, pp. 85-101. 